\title{
Effect of unilateral amygdalotomy and hypothalamotomy in patients with refractory aggressiveness
}

\author{
Luis García-Muñoz ${ }^{1,2}$, Ofir Picazo-Picazo ${ }^{3}$, José D. Carrillo-Ruíz²,4, Jesús Favila-Bojórquez ${ }^{5,6}$, \\ Fernando Corona-García ${ }^{7}$, Miguel Ángel Meza-Bautista ${ }^{8}$ and Fiacro Jiménez-Ponce ${ }^{9 *}$ \\ ${ }^{1}$ Department of Neurology and Neurosurgery, Hospital General de México "Dr. Eduardo Liceaga"; ${ }^{2}$ Department of Neurosurgery and Neurology, \\ Specialty Hospital, Centro Médico Nacional Siglo XXI, IMSS, Ciudad de México; ${ }^{3}$ Higher School of Medicine, Instituto Politécnico Nacional, Ciudad \\ de México; ${ }^{4}$ Neurosciences Coordination, Universidad Anáhuac, Ciudad de México; ${ }^{5}$ Department of Psychiatry, Specialty Hospital, Centro Médico \\ Nacional Siglo XXI, IMSS, Ciudad de México; ${ }^{6}$ Mental Hygiene, Secretaría de Salud, Ciudad de México; ${ }^{7}$ Hospitalization Service, Hospital \\ Psiquiátrico Fray Bernardino Álvarez, Secretaría de Salud, Ciudad de México; ${ }^{8}$ Department of Neurosurgery, Regional Hospital 110, IMSS, \\ Guadalajara, Jalisco; ${ }^{9}$ Sub-directorate of Hospital Regulation and Care, Instituto de Seguridad y Servicios Sociales de los Trabajadores del Estado, \\ City of Mexico, Mexico
}

\begin{abstract}
Background: Neurosurgical treatment, although controversial, is considered a useful resource in the treatment of chronic psychiatric diseases such as refractory aggressiveness. Objective: To evaluate the clinical results and side effects of posteromedial hypothalamotomy associated with amygdalotomy in patients with refractory aggressiveness. Method: $A$ clinical trial was conducted in patients with chronic aggressiveness and refractory to pharmacological treatment. A central amygdalotomy associated with posteromedial hypothalamotomy was performed using thermo-coagulation by radiofrequency. The degree of aggressiveness was quantified by the Yudofsky's global scale of aggression. Postoperative changes in aggressive behavior continued to be evaluated every 6 months for at least 36 months. Results: $A$ statistically significant change in aggressive behavior was observed during 36 months of follow-up. The collateral effects of the association of both procedures are described, the most frequent being drowsiness and some cases of reduction in sexual behavior. Conclusion: Symmetric and simultaneous unilateral lesions of the central nucleus of the amygdala and the posteromedial hypothalamus contralateral to motor dominance give the same clinical effect in the reduction of the pathological aggression that the bilateral lesions.
\end{abstract}

KEY WORDS: Limbic System. Aggressiveness. Global Aggressiveness Scale. Stereotactic Neurosurgery. Psychosurgery.

\section{Background}

"Normal" aggressive behavior has very specific objectives: to maintain the individual's physical integrity, predation for subsistence purposes, vital space or territory preservation and perpetuation of the species. These functions are perfectly summarized in the term expressed by Walter Canon", "fight or flight". Human aggressiveness shows a common pattern of behaviors similar to other animal species and is only activated in the presence of a threatening stimulus. This innate behavior is associated with the limbic system. The first description of the existence of an "emotional brain" was made by Christfried Jakob² in 1907-1908, laying the groundwork for subsequent contributions by James W. Papez in 1932 and Paul D. MacLean ${ }^{1}$. These concepts culminated in the integration of the limbic system and gave a better insight, between physiology and anatomy, in the generation and control of behavioral and emotional patterns. On the other hand, "unnatural or pathological" aggressiveness is an exaggerated behavior that occurs disproportionately in the presence of a stimulus that normally would not imply danger. This symptom is present with certain frequency in some neurological and/or psychiatric conditions.
Correspondence:

*Fiacro Jiménez-Ponce

E-mail: fiacrojimenez@yahoo.com
Date of reception: 06-03-2019

Date of acceptance: 22-03-2019

DOI: 10.24875/GMM.M19000290
Gac Med Mex. 2019;155 (Suppl 1):S49-S55

Contents available at PubMed www.gacetamedicademexico.com 
According to Yudofsky, pathological aggressive behavior is stereotyped and can be manifested by emitting noises or foul language, causing damage to objects or animals, infringing physical injuries to other people (hetero-aggressiveness) or against themselves (auto-aggressiveness) ${ }^{3}$. Yudofsky believes that aggressive behavior in patients is related to neurological or psychiatric damage, and therefore it should be considered as a "neuro-aggressive disorder". The treatment of this disorder involves the use of neuroleptic drugs, benzodiazepines, anticonvulsants, antidepressants, beta-blockers or mood modulators ${ }^{4,5}$. Pharmacological schemes are always administered in combination and for a long time. However, there is a "refractoriness" to drug treatment that for the purposes of this work is considered as an insufficient or absent response to it. Thus, electroconvulsive therapy (ECT) is proposed as another therapeutic resource.

Refractory neuro-aggressive disorder is a problem not only because of the social risk it implies, but also because of the high costs of drug treatment, frequent hospitalizations required for the control of crises and the "containment" care family members must provide to the patient.

Gotlieb Burckhardt was the one who in the $19^{\text {th }}$ century first surgically injured the frontal or temporal lobes in six psychiatric patients, with partial results and high morbidity and mortality ${ }^{6}$. Already in the $20^{\text {th }}$ century, Fulton resected the frontal cortex in simians, thus transforming normally irritable behavior into docile behavior ${ }^{1}$. These results motivated Lima and Moniz (in Portugal) and Freeman and Watts (in North America) to perform a neurosurgical section of the frontal connections to the basal nuclei in psychiatric patients. However, despite the results in many encouraging cases, this procedure, called frontal lobotomy, did not show a clear methodology, did not establish precise indications and showed high morbidity, which is why it fell into discredit ${ }^{1,7-10}$.

In parallel to the simultaneous appearance of sophisticated surgical localization techniques, the development of stereotactic brain atlases and X-ray methods facilitated establishing a relationship between limbic structures functionality and behaviors thereof derived. Thus, some anatomical structures of the limbic system became surgical targets for aggressive behavior selective treatment ${ }^{1}$.

Specifically, hypothalamotomy and amygdalotomy were separately proposed for the treatment of aggressive behavior ${ }^{7-10}$. The posteromedial hypothalamus was bilaterally injured by Sano et al. in 1966, who reported a significant reduction of aggressive behavior ${ }^{10,11}$. On the other hand, Ramamurthi and Balasubramanian also reported a significant reduction in human aggressive behavior through bilateral lesion of the central nucleus of the amygdala, thus confirming Narabayashi's results ${ }^{12,13}$. Both procedures have been proven effective in controlling refractory aggressive behavior. However, bilateral posteromedial hypothalamotomy $(\mathrm{PMH})$ can cause serious and potentially fatal hypothalamic dysfunction. Even Sano himself had recommended a waiting period of 7 to 10 days between the performance of both lesions ${ }^{11}$. For bilateral central amygdalotomy (CA), functional damage is manifested with Klüver-Bucy syndrome (agnosia, potentially dangerous visual stimuli, hyperorality and hypersexuality, among other symptoms $)^{14}$. Andy and Stephan published results suggesting that the combination of the amygdala and hypothalamus lesions did not increase the percentage of improvement of the results obtained by CA alone ${ }^{15}$.

On the other hand, already in 2012, the combination of cingulotomy and anterior bilateral capsulotomy was proposed for the control of refractory aggressive behavior ${ }^{16}$.

As a substitute therapeutic alternative for radiofrequency injury, in 2013, Franzzini treated patients with refractory aggressiveness using deep brain electrical stimulation in both posteromedial hypothalamuses $(\mathrm{PMH})^{17}$. However, the procedure is still under investigation.

Our group has already published the preliminary historical results of a case series where symmetrical unilateral $\mathrm{CA}$ and $\mathrm{PMH}$ lesions contralateral to manual dominance decreased refractory aggressive behavior in neuro-aggressive disorder ${ }^{18}$.

Thus, the main purposes of this clinical trial were to assess the clinical results and side effects of $\mathrm{PMH}$ lesions associated with CA, unilaterally, symmetrically or asymmetrically, ipsilaterally or contralaterally to manual dominance.

\section{Method}

Between 2012 and 2017, patients diagnosed with refractory aggression were treated. All patients had been referred by psychiatrists from different institutions requesting neurosurgical management for the treatment of refractory aggression. All cases were submitted to a committee composed of two psychiatrists and two functional neurosurgeons. The following requirements were established as inclusion criteria: a) 
clinical symptoms chronicity, with a history of at least 5 years; b) difficulty in controlling aggressive behavior (on a correct pharmacological treatment, for at least two years and with good therapeutic adherence) or, that in spite of an adequate clinical response, had adverse effects to the used medication such as liver dysfunction, diabetes mellitus or metabolic syndrome, and c) neuroimaging studies ruling out neoplastic, vascular, infectious, demyelinating or parasitic disease. Patients who were treated with ECT were not rejected for surgical management. In all cases, blood dyscrasias were ruled out, cardiovascular risk was determined when necessary, and brain magnetic resonance was performed, both to rule out aggregate diseases and for stereotactic surgical planning. Informed consent was requested to perform $\mathrm{CA}$ and $\mathrm{PMH}$ with radiofrequency thermo-coagulation (RFTC), which was obtained directly when patients had autonomy and were capable to decide or through the parents or legal guardians. The Explicit Aggressiveness Scale proposed by Yudofsky, or better known as Overt Aggression Scale (OAS), which is a measuring instrument validated in Mexico ${ }^{19}$, was used to measure and determine aggressive behavior. The scale includes four chapters, which consist of verbal aggressiveness, aggressiveness against objects, auto-aggressiveness and hetero-aggressiveness. Each chapter has a maximum value of 4 points and total score is 16 . The determination of motor dominance was made using the Edinburgh scale ${ }^{20}$.

Due to the nature of the condition, patients were hospitalized one day prior to the surgical procedure, maintaining their pharmacological treatment as indicated by the psychiatrist. The surgical procedure was performed under general anesthesia, and thus was the stereotactic framework placed and computed cranial tomography performed for the planning of anatomical sites. The Zamorano-Dujovny (Z-D) stereotaxic system (Fischer, Leibinger, Germany) or the Leksell framework (Elekta $A B$, Sweden) were used to locate $C A$ and $\mathrm{PMH}$. To locate the $\mathrm{PMH}$, the stereotactic coordinates reported by Sano were taken as a reference: $x=2.0 \mathrm{~mm}$ lateral to the wall of the third ventricle, $y=$ commissural midpoint and $z=2.0 \mathrm{~mm}$ below the intercomisural line. The $z$ coordinate was scanned from $4 \mathrm{~mm}$ above the site to begin electrical stimulation prior to the lesion ${ }^{11}$. For the location of CA, Andy and Stephan ${ }^{18}$ coordinates of were taken as reference, which were adjusted with the Talairach ${ }^{21}$ and Schaltenbrand and Warhen Stereotactic Brain Atlases: $x=20-26$ (24) mm for amygdala lateral component, $y=3$ to 5 (2 to 4 ) $\mathrm{mm}$ in front of the temporal horn and $z$ at $7 \mathrm{~mm}$ above the floor of the temporal ventricle (or $15 \mathrm{~mm}$ below the intercomisural line). The Stereoplan ${ }^{\circledR}$ (Fischer, Leibinger. Germany), Praezis ${ }^{\circledR}$ (Leibinger, Germany) or Framelink $^{\circledast}$ (Medtronic, USA) programs were used to calculate the coordinates in patient images. To address the nuclei, a coronal bur hole was placed $3 \mathrm{~cm}$ lateral to the midline.

In view the functional complications reported in the medical literature when bilateral lesions on the same nucleus are performed at the same time, both for the amygdaloid complex (AC) and posteromedial hypothalamus, we combined the nuclei, either simultaneously unilaterally for both or bilaterally at different times.

The AC lesion was performed with a bipolar electrode of $0.5 \mathrm{~mm}$ in diameter (Fischer, Leibinger, Germany), at $80^{\circ} \mathrm{C}$ for 90 seconds. For the hypothalamic lesion, a 0.3-mm diameter bipolar electrode (Fischer, Leibinger, Germany) was used, at $80^{\circ} \mathrm{C}$ for $60 \mathrm{sec}-$ onds, using a RFTC lesion generator ( $\mathrm{N}-50$, Fischer, Leibinger, Germany). Only for PMH were electrical stimulation tests performed using voltages between 1.0 and $8.0 \mathrm{~V}, 500-1000 \mu \mathrm{s}$ and $100 \mathrm{~Hz}$ continuously until a sympathetic response was obtained. Correct location of the electrode within the PMH caused ipsilateral mydriasis, arterial hypertension and tachycardia.

When both $\mathrm{CA}$ and $\mathrm{PMH}$ lesion was performed with RFTC at the same surgical time, the procedure was referred to as simultaneous. When the lesions of both nuclei were made in the same cerebral hemisphere, it was called symmetric. When the treated nuclei were not in the same cerebral hemisphere, for example, right $\mathrm{CA}$ and left $\mathrm{PMH}$ or vice versa, the procedure was called asymmetric. If only one nucleus was operated, $\mathrm{CA}$ or $\mathrm{PMH}$, it was referred to as unilateral. In this series, no simultaneous bilateral RFTC lesion was performed, either $\mathrm{CA}$ or $\mathrm{PMH}$, in order to avoid functional damage due to bilateral lesion.

Postoperative changes in aggressive behavior continued to be assessed every 6 months for at least 36 months with the OAS scale.

\section{Results}

The study included 12 patients, 11 men and 1 woman. Mean age was $31.8 \pm 11.48$ standard deviation (SD). Refractory pathological aggressiveness was present in eight cases with mental retardation (MR) and, in this group, four subjects did not develop language, two related to Asperger's syndrome, one to 
Table 1. This table shows the demographic data of the 12 patients who underwent amygdalotomy and posteromedial hypothalamotomy

\begin{tabular}{|c|c|c|c|c|c|c|c|c|c|}
\hline Case & Gender & Age & Comorbidity & Language & Sexuality & Type & Dominance & Medication & Adverse Effects \\
\hline LSF & M & 28 & MR & Yes & Hyper & Hetero & Right & $\begin{array}{l}\text { QTP, HPD, ZSD, } \\
\text { CBZ }\end{array}$ & Torsion dystonia \\
\hline ASF & M & 22 & MR+Asperger & No & Hyper & Hetero/Auto & Left & $\begin{array}{l}\text { OLZ, CBZ, VPM, } \\
\text { CLZ }\end{array}$ & Torsion dystonia \\
\hline AAJ & M & 23 & MR+Autism & No & NR & Hetero/Auto & Right & $\begin{array}{l}\text { QTP, HPD, ZSD, } \\
\text { CBZ }\end{array}$ & Diabetes mellitus \\
\hline $\mathrm{RCA}$ & M & 28 & MR & Yes & Hyper & Hetero & Right & $\begin{array}{l}\text { VPM, LTC, CLZ, } \\
\text { QTP, LMZ }\end{array}$ & Diabetes mellitus \\
\hline $\mathrm{NHR}$ & M & 33 & MR & No & Hyper & Hetero/Auto & Left & $\begin{array}{l}\text { HPD, LTC, PMD, } \\
\text { CLZ, LMZ }\end{array}$ & $\begin{array}{l}\text { Diabetes mellitus, } \\
\text { Thrombocytopenia, } \\
\text { Gynecomastia, } \\
\text { Metabolic syndrome }\end{array}$ \\
\hline GBMA & M & 20 & MR & Yes & NR & Hetero & Left & $\begin{array}{l}\text { MFD, ZSD, HPD, } \\
\text { RPD, VPM }\end{array}$ & $\begin{array}{l}\text { Torsion dystonia, } \\
\text { Diabetes mellitus }\end{array}$ \\
\hline BRLM & M & 32 & OCD TBI & Yes & Hyper & Hetero & Right & VPM, CBZ, QTP & Somnolence+Syalorrhea \\
\hline ACC & M & 22 & BPD & Yes & Normal & Hetero/Auto & Right & QTP, VPM, CLZ & None \\
\hline RLM & $\mathrm{F}$ & 32 & MR+Epilepsy & Yes & Normal & Hetero/Auto & Right & $\begin{array}{l}\text { VPM, LTC, PRM, } \\
\text { QTP }\end{array}$ & Thrombocytopenia \\
\hline CLC & M & 48 & SCZ & Yes & NR & Hetero/Auto & Right & HPD, QTP, VPM & Torsion dystonia \\
\hline EMZE & M & 59 & SCZ & Yes & NR & Hetero/Auto & Right & HPD, QTP, CBZ & Torsion dystonia \\
\hline GMA & M & 35 & MR +Autism & No & Normal & Hetero/Auto & Right & $\begin{array}{l}\text { CPMZ, CZP, LZP, } \\
\text { VPM }\end{array}$ & Torsion dystonia \\
\hline
\end{tabular}

OCD: obsessive compulsive disorder; MR: mental retardation; TBI: traumatic brain injury; SCZ: schizophrenia; QTP: quetiapine; HPD: haloperidol: ZSD: ziprasidone;

CBZ: carbamazepine; OLZ: olanzapine; VPM: mg valproate; CLZ: clonazepam; LTC: levetiracetam; LZP: lorazepam; MFD: methylphenidate; RPD: risperidone; PRD: primidone;

CPMZ: chlorpromazine; CZP: clozapine

autism and the other to epilepsy. Two subjects were related to schizophrenia, one to posttraumatic syndrome (who also developed obsessive-compulsive disorder) and another to borderline personality disorder. All patients showed an extreme aggressiveness pattern of 16 points, which is the highest possible score according to Yodosfsky's global scale ${ }^{2}$. Four cases showed hetero-aggressiveness and eight the combined form (hetero-aggressiveness plus auto-aggressiveness). Five male patients showed increased and uninhibited sexual behavior, manifested with public masturbation and one case was also accompanied by sexual harassment. In four cases, sexual behavior was not reported and in three it was referred to as "normal". Nine patients were right-handed. All patients received at least one neuroleptic drug (quetiapine, haloperidol, ziprasidone, olanzapine, risperidone, chloropromazine and clozapine) associated with an antiepileptic drug (carbamazepine, Mg valproate, clonazepam, primidone, levetiracetam and lorazepam). In one case, methylphenidate was used. Each patient received between three and five drugs to reduce aggressive behavior and in all cases except one, adverse effects occurred, with the most common being extrapyramidal phenomena (torsion dystonia) in six cases, diabetes mellitus in four patients, metabolic syndrome with thrombocytopenia and gynecomastia in one and another with drowsiness and sialorrhea. Nine patients received ECT prior to surgery (Table 1).

In the first five cases, unilateral RFTC of both AC and $\mathrm{PMH}$ was randomly selected simultaneously but not symmetrically. These first treated cases had to be re-operated in less than three months due to aggressive behavior relapse. With the second surgical procedure, it was observed that when completing nuclei bilaterality, whether outside the amygdala or the posteromedial hypothalamus, the therapeutic effect was achieved as long as the PMH and AC lesions of the coincided contralateral to manual dominance. The observations and analysis of these first five cases reaffirmed the data of the previous study on $\mathrm{PMH}$ and $\mathrm{AC}$ dominance. In the seven subsequent patients, site allocation was performed based on motor dominance (Table 2). 
Table 2. The random site where the procedures were performed is specified. Radiofrequency thermo-coagulation in the five first patients and the site where a second lesion was subsequently produced in order to achieve aggressive behavior reduction

\begin{tabular}{|c|c|c|c|c|c|}
\hline Case & Dominance & First procedure & Second procedure & Complementary site & Effective final target \\
\hline LSF & Right & $R A+L H$ & $L A+L H$ & LA & $R A+L A$ \\
\hline ASF & Left & $L A+L H$ & $\mathrm{RH}$ & $\mathrm{RH}$ & $\mathrm{LH}+\mathrm{RH}$ \\
\hline AAJ & Right & $R A+L H$ & $\mathrm{RH}$ & $\mathrm{RH}$ & $\mathrm{LH}+\mathrm{RH}$ \\
\hline $\mathrm{RCA}$ & Right & $\mathrm{RA}+\mathrm{LH}$ & $L A+L H$ & LA & $R A+L A$ \\
\hline $\mathrm{NHR}$ & Left & $L A+L H$ & $\mathrm{RA}+\mathrm{RH}$ & $\mathrm{RA}+\mathrm{RH}$ & $\begin{array}{l}L A+R A \\
L H+R H\end{array}$ \\
\hline
\end{tabular}

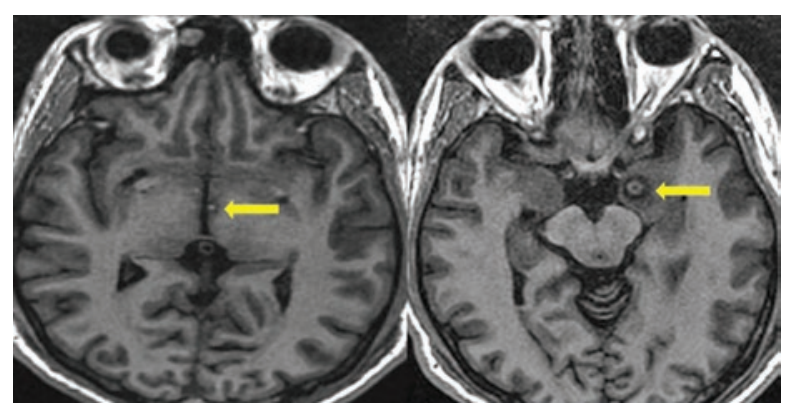

Figure 1. These two T1-weighted axial magnetic resonance images show the typical acute signals of nucleotomies produced by radiofrequency thermo-coagulation for posteromedial hypothalamotomy on the left and the $A C$ on the right (shown by yellow arrows).

For the purpose of this report, follow-up was carried out at $6,12,18,24,30$ and 36 months. The first nine cases have already reached 60 months of follow-up.

Table 3 shows the changes in the OAS-obtained values. Applying the non-parametric Wilcoxon rank test to the measurements obtained at baseline in comparison with each follow-up, a statistically significant change was observed, although the 36-month followup was not completed in the last three cases.

Figure 1 shows the typical magnetic resonance images of the immediate postoperative period after the $\mathrm{CA}$ and PHM procedures. The main side effects and changes in sexual behavior were highly important, since, in all cases, there was nearly a disappearance of sexual interest. No patient required intensive care management after surgery (Table 4).

\section{Discussion}

The results obtained in this work show a statistically significant change the aggressive behavior as assessed by the OAS scores. There was median a decrease of between 13 and 14 points over 36 months of follow-up ( $p$ between 0.002 and 0.007) (Table 3). The main purpose of this work was to identify which combination of radiofrequency lesions directed to the
Table 3. This table shows the Overt Aggression Scale (OAS) scores at baseline and over the follow-up period from 6 months to the maximum possible follow-up for each case, which in 9 patients was 36 months. Of note, except for the first two cases in whom improvement was accentuated after 6 months and after reoperation, all patients operated from the start with amygdalotomy and hypothalamotomy contralateral to the dominant hemisphere improved since the beginning. The median differences observed according to OAS were (Wilcoxon rank test): baseline vs. 6 months, -13 points $(p=0.002 ; n=12)$; baseline vs. 12 months, -14 points $(p=0.002 ; n=12)$; baseline vs. 18 months, -13 points $(p=0.003 ; n=11)$; baseline vs. 24 months, - 14 points $(p=0.003 ; n=11)$; baseline vs. 30 months, -13 points ( $p=0.005 ; n=10)$ and baseline vs. 36 months, -13 points $(p=0.007 ; n=9)$

\begin{tabular}{|c|c|c|c|c|c|c|c|}
\hline Case & Baseline & AA 6 & AA 12 & AA 18 & AA 24 & AA 30 & AA 36 \\
\hline LSF & 16 & 9 & 3 & 3 & 3 & 3 & 3 \\
\hline ASF & 16 & 12 & 2 & 3 & 2 & 2 & 2 \\
\hline AAJ & 16 & 3 & 4 & 4 & 4 & 4 & 4 \\
\hline $\mathrm{RCA}$ & 16 & 0 & 0 & 0 & 0 & 0 & 0 \\
\hline NHR & 16 & 5 & 4 & 4 & 4 & 4 & 4 \\
\hline GBMA & 16 & 0 & 0 & 0 & 0 & 0 & 0 \\
\hline BRLM & 16 & 5 & 3 & 3 & 3 & 3 & 3 \\
\hline ACC & 16 & 0 & 0 & 0 & 0 & 0 & 0 \\
\hline RLM & 16 & 5 & 4 & 4 & 4 & 4 & 4 \\
\hline CLC & 16 & 0 & 0 & 0 & 0 & 0 & NA \\
\hline EMZE & 16 & 0 & 0 & 0 & 0 & NA & NA \\
\hline GMA & 16 & 0 & 0 & NA & NA & NA & NA \\
\hline Median & 16 & 3.25 & 16.7 & 1.91 & 1.82 & 2.00 & 2.22 \\
\hline SD & 0 & 40.7 & 1.83 & 1.87 & 1.83 & 1.83 & 1.79 \\
\hline
\end{tabular}

AA: aggressiveness assessment; SD: standard deviation; NA: not accessible.

center of the amygdaloid nucleus or posteromedial hypothalamus lesion could be more effective in producing a clinical change. The assessment of the first five cases where the reappearance of neuro-aggressive syndrome symptoms almost immediately guided this group of researchers to consider the combination 
Table 4. Posteromedial hypothalamotomy and central amygdalotomy side effects are described. Seven out of 12 patients showed side effects, with the most common being somnolence. In no case was any side effect definitive. The effect on sexual behavior is also described. Four out of five cases had their sexual behavior decreased.

\begin{tabular}{|c|c|c|c|}
\hline Case & $\begin{array}{l}\text { Immediate postoperative side effects (between } 7 \text { and } \\
14 \text { days' duration) }\end{array}$ & Preoperative sexuality & Postoperative sexuality \\
\hline LSF & Somnolence & $\begin{array}{l}\text { Hypersexuality } \\
\text { Pederasty }\end{array}$ & $\begin{array}{l}\text { Reduction } \\
\text { Pederasty disappearance }\end{array}$ \\
\hline ASF & None & $\begin{array}{l}\text { Hipersexuality } \\
\text { Self-inflicted anal laceration with objects }\end{array}$ & Disappearance \\
\hline AAJ & Somnolence & Not reported & Not reported \\
\hline $\mathrm{RCA}$ & Somnolence & Hipersexuality & Disappearance \\
\hline NHR & None & Hipersexuality & Reduction \\
\hline GBMA & None & Not reported & Not reported \\
\hline BRLM & None & Hipersexuality & No changes \\
\hline ACC & None & Normal & No changes \\
\hline RLM & Brachial monoparesis, anorexia, somnolence, hyperthermia & Normal & No changes \\
\hline CLC & Somnolence & Not reported & Not reported \\
\hline EMZE & Somnolence, Anorexia & Not reported & Not reported \\
\hline GMA & Somnolence, hypotension (requiring amines) & Normal & Reduction \\
\hline
\end{tabular}

of symmetric amygdalotomy and hypothalamotomy contralateral to manual dominance as the first surgical option. The previous work of this same group had glimpsed this possibility ${ }^{18}$. Thus, the main contribution of this work has been the measurement of the changes obtained by CA and PMH RFTC using a standardized instrument in patients followed for 36 months, as well as to describe that aggressiveness can have a hemispheric laterality shared with manual dominance.

Other previous works, such as those reported by this same group in 2012, had already found that multiple lesion of frontal projections to basal nucleus structures can decrease aggressive behavior at the expense of diminishing executive functions ${ }^{16}$. The reports of all previous authors who have already informed on the effectiveness of the $\mathrm{CA}$ and $\mathrm{PMH}$ procedure have not been followed for so long and have not used an instrument validated in Mexico ${ }^{10-16}$.

However, this work is still a preliminary study that seeks a surgical option in cases of patients with refractory aggression that have not improved in their clinical, family and social conditions with conventional treatments. The main limitations of this work correspond to those inherent to a self-controlled pilot study and are the small number of cases included and the lack of a control group. However, except for Ramamurti ${ }^{12}$ studies, most published articles are on case series with a small number of enrolled patients and no control group, which is not possible because a surgical procedure of this type cannot be compared with a randomly assigned surgery simulation.

Although a self-controlled study was conducted and a non-parametric statistical test (Wilcoxon rank test) was applied, it is necessary to extend the experience in other groups of researchers dedicated to this field of medicine.

Left-handed ASF patient improved his clinical conditions by completing the right hypothalamus RFTC, considering that he had already undergone a left amygdala and hypothalamus lesion. In this particular case, the combination of the two hypothalamus and the non-dominant amygdala improved the patient's conditions and drive us to think that the assessment of dominance might be difficult sometimes or that multiple lesions, as in the case of bilateral capsulotomy and cingulotomy, are also effective.

The mechanism of action of these surgical procedures has already been discussed in works of the original authors, who have referred to the interruption of the limbic system as the main explanation of the mechanism of action of these procedures ${ }^{10-13}$.

This group of researchers believes that it would be interesting to explore the effects of these same 
cerebral nuclei with deep brain electrical stimulation, where randomization and blinding could be used. When implanting a patient with brain electrodes, and after informed consent, patients can be randomly selected to be under stimulation or without it, and since stimulation is silent in terms of its local action it is also relatively easy for a double or triple blind study to be designed. However, no such clinical trial has been carried out.

It is clearly necessary that another group of researchers consider replicating the observations on aggressive behavior hemispheric dominance. Left dominance of language and of certain executive functions might guide on the possibility that aggressive behavior might not only be an instinctive activity but rather a motor activity planned and executed to achieve a specific objective, such as directing aggression towards the attainment of territory, of satisfiers or hierarchical level.

It would be important assessing the genetic, hormonal and epigenetic conditions of patients with a neuro-aggressive syndrome; strikingly, in most case series reports of neurosurgically-treated patients, the study subjects are males. Finally, the possibility of performing less invasive procedures such as radiosurgery or deep brain stimulation is so far a pending chapter that is limited by the feasibility of obtaining neuromodulation equipment.

\section{Conclusions}

This study concludes that symmetric and simultaneous RFTC-produced unilateral lesions of the central nucleus of the amygdala and posteromedial hypothalamus contralateral to motor dominance produce the same clinical effect on reducing pathological aggressiveness than bilateral lesions.

\section{References}

1. Faria MA. Violence, mental illness, and the brain - A brief history of psychosurgery: Part 3 - From deep brain stimulation to amygdalotomy for violent behavior, seizures, and pathological aggression in humans. Surg Neurol Int. 2013;4:91.

2. Yudofsky SC, Silver JM, Jackson W, Endicott J, Williams D. The Overt Aggression Scale for the objective rating of verbal and physical aggression. Am J Psychiatry. 1986;143:35-9.

3. Edlinger M, Welte AS, Yalcin-Siedentopf N, Kemmler G, Neymeyer F, Fleischhacker WW, et al. Trends in pharmacological emergency treatment of patients suffering from schizophrenia over a 16-year observation period. Int Clin Psychopharmacol. 2018;33:197-203.

4. Taber KH, Hurley RA, Yudofsky SC. Diagnosis and treatment of neuropsychiatric disorders. Annu Rev Med. 2010;61:121-33.

5. Rojas G P, Arancibia S P, Bravo S V, Varela G S. Diabetes mellitus inducida por olanzapina: Caso clínico. Rev Méd Chile. 2001;129:1183-5.

6. Escobar-Córdoba F, Suárez-Beltrán MF. Abordaje clínico del paciente violento en atención primaria. Universitas Médica. 2011;52:421-30.

7. Jiménez-Ponce F, García-Muñoz L, Carrillo-Ruiz JD. The role of bioethics in the neurosurgical treatment of psychiatric disorders. Rev Med Hosp Gen Mex. 2015;78:47-54

8. Yampolsky C, Bendersky D. Cirugía de los trastornos del comportamiento: el estado del arte. Surg Neurol Int. 2014;5:S211-31.

9. Caruso JP, Sheehan JP. Psychosurgery, ethics, and media: a history of Walter Freeman and the lobotomy. Neurosurg Focus. 2017;43:E6.

10. Sano K, Yoshioka M, Ogashiwa M, Ishijima B, Ohye CJS. Postero-medial hypothalamotomy in the treatment of aggressive behaviors. Confin Neurol. 1966:27:164-7.

11. SanoK. Aggressiveness. In: Schaltenbrand G, WalkerAE, editors. Stereotaxy of the human brain. Anatomical, physiological and clinical application. Stuttgart: Georg Thieme Verlag; 1982..617.21.

12. Ramamurthi B. Stereotactic operation in behaviour disorders. Amygdalotomy and hypothalamotomy. En: Personality and neurosurgery. Springer; 1988. pp. $152-7$.

13. Narabayashi $\mathrm{H}$, Uno MJS. Long range results of stereotaxic amygdalotomy for behavior disorders. Confin Neurol. 1966;27:168-71.

14. Ledo-Varela MT, Gimenez-Amaya JM, Llamas A. [The amygdaloid complex and its implication in psychiatric disorders]. An Sist Sanit Navar. 2007;30:61-74.

15. Walker AE, Hassler R, Schaltenbrand G, Andy OJ. Stereotaxy of the human brain: anatomical, physiological and clinical applications. Stuttgart: Georg Thieme Verlag; 1982.

16. Jiménez $F$, Soto JE, Velasco $F$, Andrade P, Bustamante JJ, Gómez P, et al. Bilateral cingulotomy and anterior capsulotomy applied to patients with aggressiveness. Stereotact Funct Neurosurg. 2012;90:151-160.

17. Franzini A, Broggi G, Cordella R, Dones I, Messina GJWn. Deep-brain stimulation for aggressive and disruptive behavior. 2013;80:S29.

18. Garcia-Munoz L, Carrillo-Ruiz J, Favila-Bojorquez J, Lopez-Valdes J, Jimenez-Ponce FJ. Treatment of refractory aggressiveness by amygdalotomy and posteromedial hypothalamotomy by radiofrequency. 2019;68:91-8.

19. Páez F, Licon E, Fresán A, Apiquian R, Herrera-Estrella M, García-Anaya $\mathrm{M}$, et al. Estudio de validez y confiabilidad de la escala de agresividad explícita en pacientes psiquiátricos. 2002;25:21-6.

20. Oldfield RC. The assessment and analysis of handedness: the Edinburgh inventory. 1971;9:97-113.

21. Talairach JJ, Tournoux P. Co-planar stereotaxic atlas of the human brain-3-dimensional proportional system: An Approach to Cerebral Imaging. 1988;39:145 